\title{
Sertoli Cell Tumor of the Testis in Association with Peutz-Jeghers Syndrome Sometimes Requires a High Index of Suspicion
}

\author{
García González M. ${ }^{1}$, Moreno Álvarez A. ${ }^{2}$, Dargallo Carbonell T. ${ }^{1}$, Solar Boga A. ${ }^{2}$, \\ Suarez Dono I. ${ }^{3}$, Mosquera Reboredo J. ${ }^{4}$ and Vela Nieto D. ${ }^{1}$ \\ ${ }^{1}$ Department of Pediatric Surgery. A Coruña University Hospital, Spain \\ ${ }^{2}$ Pediatric Gastroenterology Unit. Department of Pediatrics. A Coruña University Hospital, Spain \\ ${ }^{3}$ Department of Radiology. A Coruña University Hospital, Spain \\ ${ }^{4}$ Department of Pathology. A Coruña University Hospital, Spain
}

Correspondence should be addressed to: Miriam Garcia; mir_milenio@hotmail.com

Received Date: 25 January 2014; Accepted Date: 5 June 2014; Published Date: 30 December 2014

Academic Editor: Anna Grandone

Copyright (C) 2014 García González M., Moreno Álvarez A., Dargallo Carbonell T., Solar Boga A., Suarez Dono I., Mosquera Reboredo J. and Vela Nieto D. Distributed under Creative Commons CC-BY 3.0

\begin{abstract}
Peutz Jeghers Syndrome (PJS) is an autosomal dominant disorder characterized by mucocutaneous pigmentation and hamartomatous polyps throughout the gastrointestinal tract. Pigmented macules appear especially on oral mucosa, lips and fingers. Hamartomatous polyps are found predominantly at the small intestine and colon lesser extent ${ }^{1}$ and can cause bleeding and abdominal pain secondary to intussusception, intestinal obstruction and infarction. Approximately $80 \%$ of patients with PJS have mutations in threonine kinase 11 (STK11) located in 19p13.3 chromosome ${ }^{1,2}$. This acts as a tumor suppressor gen, leading its mutation to increased risk of cancer at an early age ${ }^{3}$. Most commonly reported cancers are luminal gastrointestinal and breast. Testicular tumors are less known, but may be present at early $a^{2} e^{2}$ and course with estrogenic manifestations in most of cases.
\end{abstract}

We report a case of PJS with intratubular large cell hyalinizing Sertoli Cell (LCHSC) tumor of the test is diagnosed during the follow-up of the patient.

Keywords: Peutz-Jeghers syndrome, testicular neoplasm, Sertoli cell tumor, gynecomastia.

\section{Introduction}

Peutz Jeghers syndrome (PJS) is an $\mathrm{AD}$ disorder with variable penetrance and expressivity that is typically characterized by mucocutaneous pigmentation and gastrointestinal hamartomatous polyps. Pigmented lesions clinically manifest as perioral melanosis on the oral mucosa, fingers and tongue. Typically absent at birth, they developed during childhood and decrease throughout the years. The

Cite this Article as: García González M., Moreno Álvarez A., Dargallo Carbonell T., Solar Boga A., Suarez Dono I., Mosquera Reboredo J. and Vela Nieto D. (2014), "Sertoli Cell Tumor of the Testis in Association with PeutzJeghers Syndrome Sometimes Requires a High Index of Suspicion," Pediatrics Research International Journal, Vol. 2014 (2014), Article ID 704812, DOI: 10.5171/2014.704812 
hamartomatous polyps are located predominantly at the level of the small intestine and can cause chronic abdominal pain, bleeding and intussusception, but their malignant degeneration is rare. Many patients with PJS have a mutation in the STK11 gene (with an estimated incidence of $70 \%$ cases), tumor suppressor gene located on the short arm of chromosome 19, which predisposes them to suffer various types of malignancies. Testicular injuries can suffer these patients are less well known and may debut as early as childhood. In most of the cases described, they are associated with estrogenic manifestations, where gynecomastia secondary to increased activity of the aromatase enzyme is characteristic.

To our knowledge, there are only two series of patients published for this purpose: 4 cases filed in 2001 and the last dating from 2008 where 8 cases of large cell testicular tumor associated with sertoli SPJ. The rest of the publications present isolated cases of patients suffering from this syndrome still a total of 24 cases reported worldwide.

\section{Case Report}

A child with family history of PJS in mother and grandmother was referred to our hospital with four years old because of prolapsed rectal polyp. Polypectomy was carried out and genetic study confirms the PJS, with a delection that includes exons 2 to 10 of STK11 gene.

During his childhood polypectomy was necessary at eleven years old for polyp removal in mid-jejunum, hepatic flexure colon and sigma due to abdominal pain and chronic lower gastrointestinal bleeding. A year later three polyps in the rectum were excised. All removed polyps were hamartomatous, without atypia or malignancy signs.

At the age of 12 years and four months, testicular ultrasonography was performed as part of the monitoring protocol. Testicles were slightly increased in size and there were multiple echogenic images (Fig. 1) predominantly in right testis due to calcification, the larger $2.6 \mathrm{~mm}$. (Fig.2) The patient was asymptomatic.

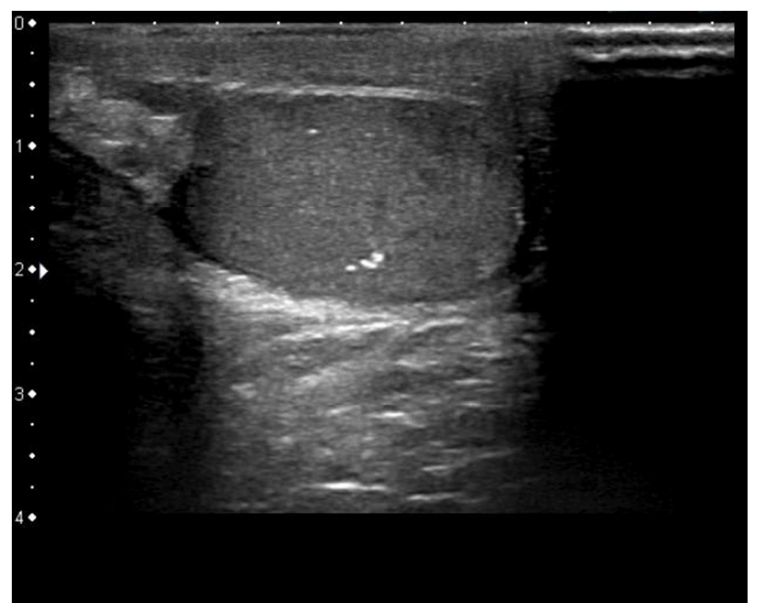

Fig. 1: Testicular Ultrasound Showing Multiple Calcifications 


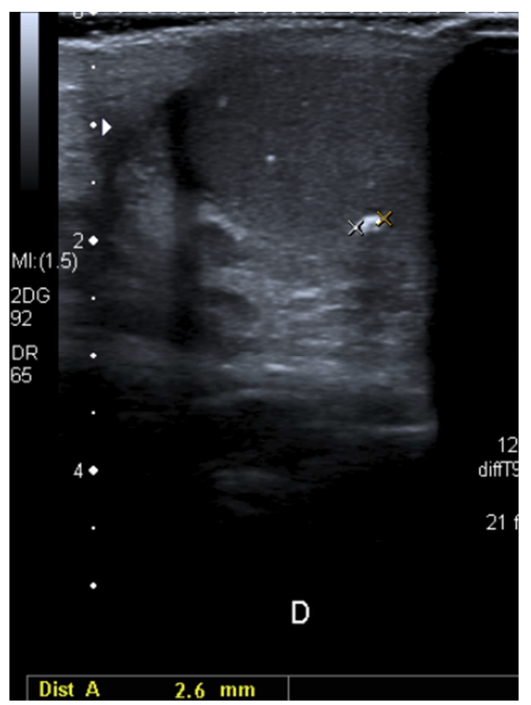

Fig. 2: Testicular Echogenic Images, the Larger $2.6 \mathrm{~mm}$, in the Right Testis.

On physical examination the boy had perioral melanosis, pubertal stage G2P2 and testicular volumen of $6 \mathrm{ml}$. In the context of obesity, he presented adipose tissue in breast, with little glandular tissue support mild gynecomastia. Laboratory tests showed LH: $2.1 \mathrm{mIU} / \mathrm{ml}$ (normal range: 1-12), FSH: $1 \mathrm{mUI} / \mathrm{ml}$ (normal range 1-12), total testosterone: 69 ng/dl (normal value for Tanner 2) and estradiol $<10 \mathrm{pg} / \mathrm{ml}$. Growth velocity was normal and bone age according to chronological age.
Because of ultrasound findings testicular biopsy was performed. It revealed testicular maturation slightly delayed for age with no spermatogonial proliferation. On this maturational delay, isolated tubules were observed with varying thickening of the basement membrane. Inside tubules stands Sertoli cells, with wide eosinophilic cytoplasm and a nucleus with spherical small nucleoli. No atypia or mitosis were found (Fig. 3 and 4). All of these histological findings are consistent with LCHSC.

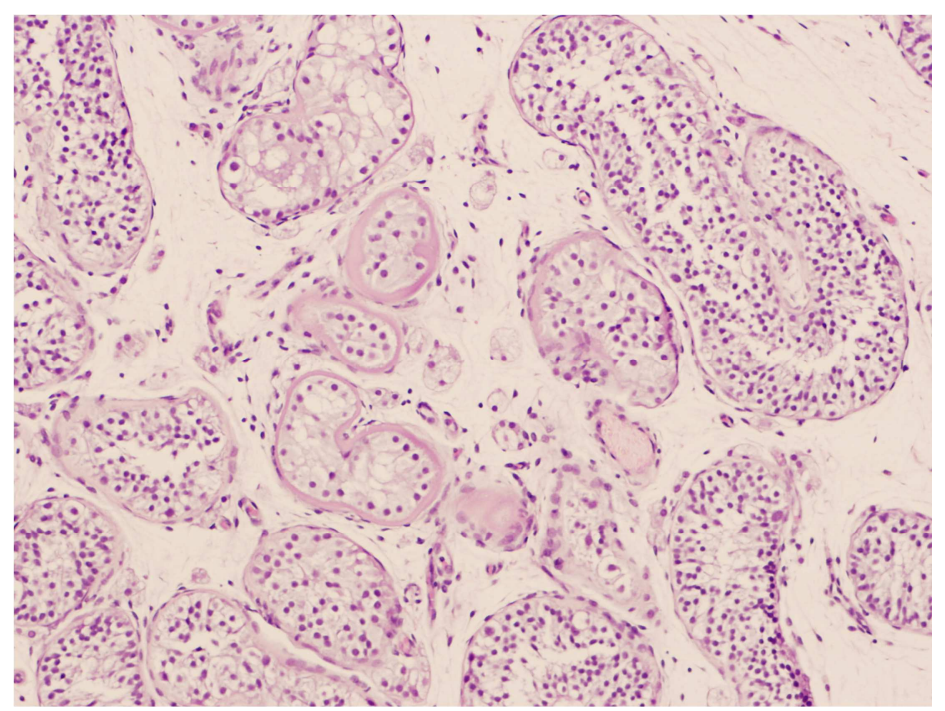

Fifg. 3: Seminiferous Tubules with Thickened Basement Membrane without Germ Cells and Sertoli Cell Proliferation with Slightly Enlarged Nuclei and Large Cytoplasm. 


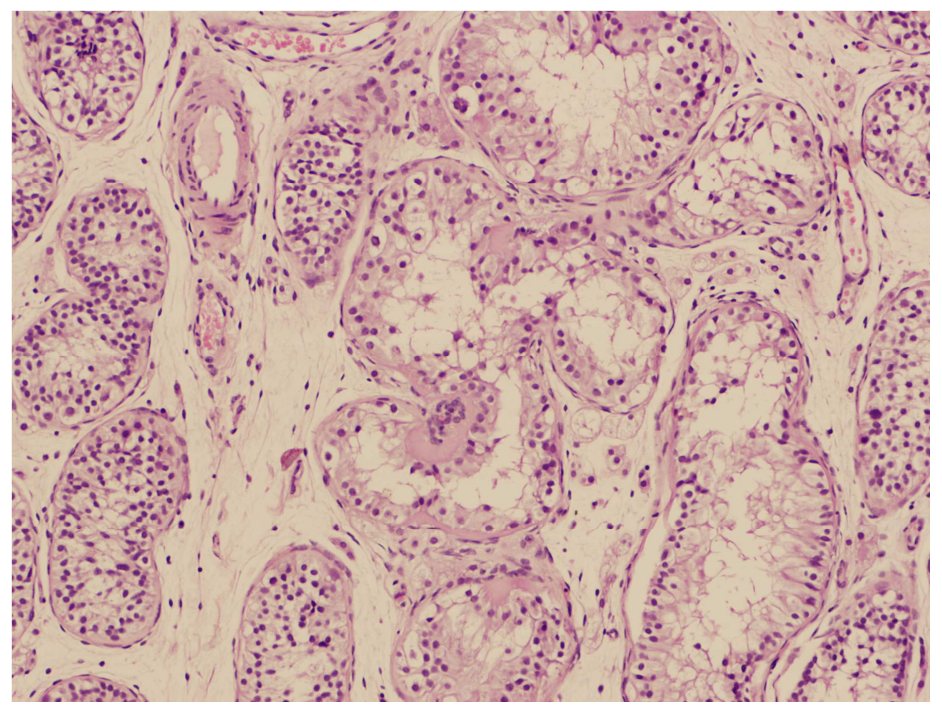

\section{Fig.4: The Nests are the Foci of Intratubular Neoplasia Sertoli Cells. Around the Tubules are Some Germ Cells but Not Observed Mature Germ Cells.}

\section{Comment:}

Patients with PJS may develop testicular neoplasms in a variable percentage of cases ${ }^{4}$. These belong to stromal tumors derived from Sertoli cells ${ }^{5}$. The large-cell calcifying Sertoli cell tumor was first described by Proppe and Scully6. In most cases it appears in phenotypically normal patients as a single, firm nodule but up to one third of cases ${ }^{5}$ are associated with genetic or endocrine syndromes as Carney Syndrome or PJS. In such cases neoplasms are commonly bilateral, multifocal, smaller and they appear earlier ${ }^{5,7}$, as in our patient. The testicular lesion specifically associated with PJS is called Intratubular large cell hyalinizing Sertoli Cell (LCHSC) neoplasia 7 and is similar to the sex cord tumor with annular tubules of the ovary that appears in women with PJS ${ }^{8}$.

Histologically, the lesion shows a patchy distribution of enlarged tubules, which exceed several times the diameter of unaffected tubules. Sertoli tumor cells are large with vacuolated and eosinophilic cytoplasm. Tubules can be replaced by basement membrane deposits, giving a hyalinized appearance ${ }^{7}$. Another feature is the presence of calcifications, not always present in cases of $\mathrm{PJS}^{7,9}$, but seen in our patient. In some cases Intratubular Sertoli Cell Proliferations (ISCPs) have been described. They emerge from seminiferous tubules and gradually replace the cell population. There is controversy about whether ISCPs are non-neoplasic proliferative lesions with malignant potential or represent an intraepithelial stage of tumor development. Although in some patients ISCPs are the only pathological finding, they may appear nearby to large-cell calcifying Sertoli cell tumor ${ }^{10}$. Some authors argue that they are the testicular neoplasm specifically associated to PJS 7,11 .

Extratubular growth implies potentially malignant nature irrespective of local characteristics ${ }^{4}$. Malignancy is found in approximately $17 \%$ of patients with largecell calcifying Sertoli cell tumor ${ }^{9}$, usually in older patients with unilateral and unifocal mass $^{8,9}$. In patients with PJS reviewing of published cases finds that local infiltration is very uncommon, so the process often remains confined to the tubules for long periods of time ${ }^{2}$. Anyway, it should be note that the follow-up period of these patients is limited since first cases date from the 80's and progression to invasive tumor cannot be rule out ${ }^{12}$. Venara et al $^{10}$ described a patient with a follow up of more than 30 years with no evidence of progression. Although histological malignancy index have been described (high mitotic rate, nuclear atypia, necrosis and vascular or lymphatic invasion) ${ }^{8,9}$, the question of which damage may progress is still unknown 7 . 
Tumor cells have increase activity of aromatase enzyme ${ }^{10}$, which normally is produced by Leydig cells ${ }^{9}$. This determine a higher conversion of testosterone to estradiol. As a result, patients with LCHSC typically have clinical signs of estrogenic activity that lead to the suspicion of the tumor, such as acceleration of growth with advanced bone age ${ }^{9}$ and gynecomastia ${ }^{10}$. However, cases of incomplete penetrance have been already described 15 and peripubertal gynecomastia not necessarily related to the tumor was appreciated in our patient.

The course of evolution of this condition justifies its conservative management monitoring by ultrasounds. Surgery could be indicated in selected cases of unusual invasive tumors, pain or mass effect. Hormonal manifestations could be treated with aromatasa inhibitors ${ }^{13}$, like testolactone and anastrozol. These drugs can be effective in controlling the clinical features of the disease, like breast development, growth velocity and bone maduration ${ }^{16}$ but evidence is limited and further studies are required 9. In our patient no hormonal abnormalities were found and bone age and growth was normal so it was decided to keep monitoring. Later ultrasound controls show no change compared to previous.

The case reported here represents an unusual presentation because it appears in an asymptomatic boy with almost no estrogenic manifestations unless mild gynecomastia. The lesion was diagnosed during a routine check, which should make us question the kind of monitoring strategies in these patients with increased risk of cancer. In case of testicular neoplasms surveillance strategies are based on expert opinion only. It is recommended to perform annual physical examination and ultrasound in case of detection abnormalities or signs of precocious puberty ${ }^{1}$. Anyway, it should be noted that average age of presentation of these tumors is earlier than in others cancers associated to $\mathrm{PJS}^{1,4,8}$. As in our case, diffuse and bilateral testicular involvement can overlook the presence of changes on physical examination ${ }^{13}$ and the development of secondary hormonal disturbances may not be present at an early stage.
Hyperestrogenism cannot be detected in laboratory tests because the hormone excess is limited to testicular aromatase ${ }^{14}$, which may explain the findings in our patient.

\section{Conclusions}

Our case highlights the need to establish a high index of suspicion of testicular tumors in patients with PJS. Although LCHSC usually remains confined locally, can lead to endocrine disorders with impact on growth and pubertal development in children. It is necessary to establish preventive diagnostic strategies from an early age in these patients.

\section{Acknowledgments}

The authors thank Dr. M. Nistal, Department of Pathology, La Paz University Hospital, for providing histopathological assistance.

\section{References}

1. Beggs, A. D., Latchford, A. R., Vasen, H. F. et al. (2010). "Peutz Jeghers Syndrome: A Systematic Review and Recommendations for Management," Gut. 59(7):975-86.

2. Dreyer, L., Jacyk, W. K. \& du Plessis, D. J. (1994). "Bilateral Large-Cell Calcifying Sertoli Cell Tumor of the Testes with Peutz Jeghers Syndrome: A Case Report," Pediatric Dermatology. 11(4):335-7.

3. van Lier, M. G., Wagner, A., MathusVliegen, E. M. et al. (2010). "High Cancer Risk in Peutz-Jeghers Syndrome: A Systematic Review and Surveillance Recommendations," American Journal of Gastroenterology. 105(6):1258-64.

4. Ulbright, T. M., Amin, M. B. \& Young, R. H. (2007). "Intratubular Large Cell Hyalinizing Sertoli Cell Neoplasia of the Testis: A Report of 8 Cases of a Distinctive Lesion of the Peutz-Jeghers Syndrome," American Journal of Surgical Pathology. 31(6):827-35.

5. Ahmed, H. U., Arya, M., Muneer, A., Mushtaq, I. \& Sebire, N. J. (2010). "Testicular and Paratesticular Tumours 
in the Prepubertal Population," The Lancet Oncology. 11(5):476-83.

6. Proppe, K. H. \& Scully, R. E. (1980). "Large-Cell Calcifying Sertoli Cell Tumor of the Testis," American Journal of Clinical Pathology. 74(5):607-19.

7. Young, R. H. (2008). "Testicular Tumors Some New and a Few Perennial Problems," Archives of Pathology \& Laboratory Medicine. 132(4):548-64.

8. Kratzer, S. S., Ulbright, T. M., Talerman, A. et al. (1997). "Large Cell Calcifying Sertoli Cell Tumor of the Testis: Contrasting Features of Six Malignant and Six Benign Tumors and a Review of the Literature," American Journal of Surgical Pathology. 21(11):1271-80.

9. Gourgari, E., Saloustros, E. \& Stratakis, C. A. (2012). "Large-Cell Calcifying Sertoli Cell Tumors of the Testes in Pediatrics," Current Opinion in Pediatrics. 24(4):51822.

10. Venara, M., Rey, R., Bergadá, I. et al. (2001) "Sertoli Cell Proliferations of the Infantile Testis: An Intratubular form of Sertoli Cell Tumor?," American Journal of Surgical Pathology. 25(10):1237-44.

11. Amin, M. B., Young, R. H. \& Scully, R. E. (2001). 'Large Cell Hyalinizing Sertoli Cell Tumor of the Testis: A Distinctive Estrogenic Tumor of Boys with Peutz-
Jeghers Syndrome (PJS). A Report of Six Cases,' Modern Pathology. 14:100.

12. Young, R. H. (2005). "Sex Cord-Stromal Tumors of the Ovary and Testis: Their Similarities and Differences with Consideration of Selected Problems," Modern Pathology. 18 Suppl 2; S81-98.

13. Kara, C., Kutlu, A. O., Tosun, M. S. et al. (2005). "Sertoli Cell Tumor Causing Prepubertal Gynecomastia in a Boy with Peutz-Jeghers Syndrome: The Outcome of 1-Year Treatment with the Aromatase Inhibitor Testolactone," Hormone Research in Paediatrics. 63(5):252-6.

14. Young, S., Gooneratne, S., Straus, F. H. 2nd. et al. (1995). "Feminizing Sertoli Cell Tumors in Boys with Peutz-Jeghers Syndrome," American Journal of Surgical Pathology. 19(1): 50-8.

15. Lefevre, H., Bouvattier, C., Lahlou, N. et al. (2006). "Prepubertal Gynecomastia in Peutz-Jeghers Syndrome: Incomplete Penetrance in a Familial Case and Management with an Aromatase Inhibitor," European Journal of Endocrinology. 154(2):221-7.

16. Grandone, A., del Giudice, E. M., Cirillo, G., Santarpia, M., Coppola, F. \& Perrone, L. (2011). "Prepubertal Gynecomastia in Two Monozygotic Twins with PeutzJeghers Syndrome: Two Years' Treatment with Anastrozole and Genetic Study," Hormone Research in Paediatrics. 75(5):374-9. 